\title{
ESTIMATING THE VARIANCE OF DENSITY AT CONSTANT HEIGHT FROM CONSTANT PRESSURE DATA
}

\author{
CONRAD P. MOOK \\ Diamond Ordnance Fuze Laboratories, Department of the Army, Washington, D. C. \\ [Manuscript recelved February 4, 1958; revised August 11, 1958]
}

\section{ABSTRACT}

\begin{abstract}
A method is presented for utilizing atmospheric statistics developed for constant pressure surfaces in estimating the variance of density at constant height. The method depends upon recent advances in the study of the interrelation of atmospheric statistics.
\end{abstract}

\section{INTRODUCTION}

The determination of the variation with altitude of the standard deviation of density is of interest in many problems in aeronautics and ballistics. Dines [1] was perhaps the first to present observational upper-air data showing the magnitude of the variability of density about the mean at certain fixed altitudes. His data extended upward to $13 \mathrm{~km}$.

However, in recent years, the practice of compiling upper-air statistics in terms of constant pressure surfaces rather than at intervals of constant altitude has become almost universal among the meteorological services of the world. This, though admirable from the point of view of synoptic meteorology, presents certain difficulties to those interested in obtaining summarized data for constant heights. The purpose of this report is to outline a procedure for approximating the vertical distribution of the standard deviation of density at constant height levels from constant pressure level statistics.

\section{THE VARIABILITY OF DENSITY AT FIXED ALTITUDES}

In 1919 Dines [1] showed how the standard deviation of the density at a given altitude could be estimated from the standard deviations of pressure and temperature. In Dines' derivation, the equation of state is differentiated logarithmically to obtain:

$$
\frac{d \rho}{\rho}=\frac{d P}{P}-\frac{d T}{T}
$$

Writing $d, p$, and $t$ for the percentage variations of the quantities and squaring the result, he obtained:

$$
\Sigma\left(d^{2}\right)=\Sigma\left(p^{2}\right)+\Sigma\left(t^{2}\right)-2 \Sigma(p t)
$$

which for small values of each term in equation (1), becomes

$$
\left(\frac{\sigma_{P}}{\rho}\right)^{2}=\left(\frac{\sigma_{P}}{P}\right)^{2}+\left(\frac{\sigma_{T}}{T}\right)^{2}-2 r_{P T}\left(\frac{\sigma_{P}}{P}\right)\left(\frac{\sigma_{T}}{T}\right)
$$

Therefore the problem of determining the standard deviation of density expressed in percent at constant altitude becomes that of determining the percentage standard deviations of pressure and temperature at constant altitude and their coefficient of correlation. However as stated previously, data are now being made available only in terms of constant pressure surfaces. Table 1 contains data of this type for Goose Bay for January 1952.

The initial problem which we set out to solve in this study is to determine from the data shown in table 1 the corresponding standard deviations of pressure and temperature at constant altitude surfaces. A method of converting information, such as that shown in table 1 , into the required form will be presented. The resulting standard deviations of density expressed in percent are then compared with similar statistics obtained by direct interpolations of density from constant pressure surfaces to fixed altitude levels.

\section{DETERMINING STANDARD DEVIATION OF PRESSURE AT CONSTANT ALTITUDE}

Buell [2] stated recently that "it seems intuitively obvious that the parameters used to describe the state of the atmosphere should be highly variable together or relatively constant together." Klein [3] has prepared maps in which standard deviations of pressure at fixed levels are used interchangeably with standard deviations of height of constant pressure surfaces, after applying a

TABLE 1.-Average temperature and height for constant pressure

\begin{tabular}{|c|c|c|c|c|}
\hline$\underset{(\mathrm{mb} .)}{P}$ & $\left(\begin{array}{c}\vec{T} \\
\left({ }^{A} .\right)\end{array}\right.$ & $\sigma_{T_{i}}$ & $\left(\begin{array}{c}\bar{x} \\
(\mathrm{~m} .)\end{array}\right.$ & $\sigma_{1}$ \\
\hline $\begin{array}{l}850 \\
600 \\
3500 \\
200\end{array}$ & $\begin{array}{l}256.35 \\
248.60 \\
226.70 \\
218.82 \\
215.59\end{array}$ & $\begin{array}{l}\text { 7. } 33 \\
6.05 \\
\text { 4. } 61 \\
\text { 5. } 99 \\
4.45\end{array}$ & $\begin{array}{r}1319.27 \\
3903.53 \\
7648.24 \\
11256.57 \\
15654.14\end{array}$ & $\begin{array}{l}65.37 \\
105.58 \\
169.50 \\
164.65 \\
154.78\end{array}$ \\
\hline
\end{tabular}
surfaces and their standard deviations, Goose Bay, Labrador, January 1952. 
constant conversion factor based on the hydrostatic assumption. The factor to be used can be conveniently obtained from the Smithsonian Meteorological Tables (Table 60) [4].

Thus the height change statistics in table 1 may be converted to pressure change statistics using the factor appropriate to the mean temperature at the given pressure surface. For example, for an assumed mean temperature of $-20^{\circ} \mathrm{C}$. at $600 \mathrm{mb}$., the ratio is $8.1 \mathrm{mb}$. per $100 \mathrm{~m}$., and therefore the standard deviation of pressure at constant level in the vicinity of $600 \mathrm{mb}$. becomes:

$$
\sigma_{P}=\frac{105.58(8.1)}{100}=8.44 \mathrm{mb} \text {. }
$$

\section{DETERMINING STANDARD DEVIATION OF TEMPER- ATURE AT CONSTANT ALTITUDE}

Stidd [5] has shown that the well known correlations between pressure and temperature at constant height (first presented by Dines [1]), also exist as a relationship between height and temperature at constant pressure. Therefore if a given temperature change in a constant pressure surface is associated with a change in height of that surface, the relationship can be used to determine approximately the temperature change which would occur at constant elevation.*

The coefficient of correlation $r_{h T}$ may be computed directly or may be inferred from $\sigma_{h}$ and $\sigma_{T}$ statistics using the method of Stidd [5]. Both are shown in figure 1 which describes Goose Bay data for January 1952.

The average departure from mean temperature associated with a departure of one meter in the beight of the constant pressure surface is, at $600 \mathrm{mb}$.:

$$
b=r_{h T} \frac{\sigma_{T_{i}}}{\sigma_{n}}=.76 \frac{6.05}{105.58}=.043
$$

where $\sigma_{T_{i}}$ is the standard deviation of temperature at constant pressure.

Therefore at constant pressure, a 100-meter departure of height from the mean is associated with a $4.3^{\circ}$ départure in temperature (of the same sign). Interpreted in terms of an increase in height of 100 meters, the increase in temperature which would occur at constalit height would be approximately $.65^{\circ} \mathrm{C}$. greater than that at constant pressure, assuming a normal rate of decrease in temperature with altitude, as specified in the U. S. Standard Atmosphere in the troposphere [7].

Therefore

$$
\sigma_{T}=\frac{4.95}{4.3} \sigma_{T_{i}}=1.15 \sigma_{T_{i}}
$$

where $\sigma_{T}$ is the standard deviation of temperature at constant altitude.

At $600 \mathrm{mb}$. (from table 1)

$$
\sigma_{T}=1.15(6.05)=6.96
$$

* Since the submission of this paper, the author has seen a paper by Crossley [6] discussing the inverse problem.

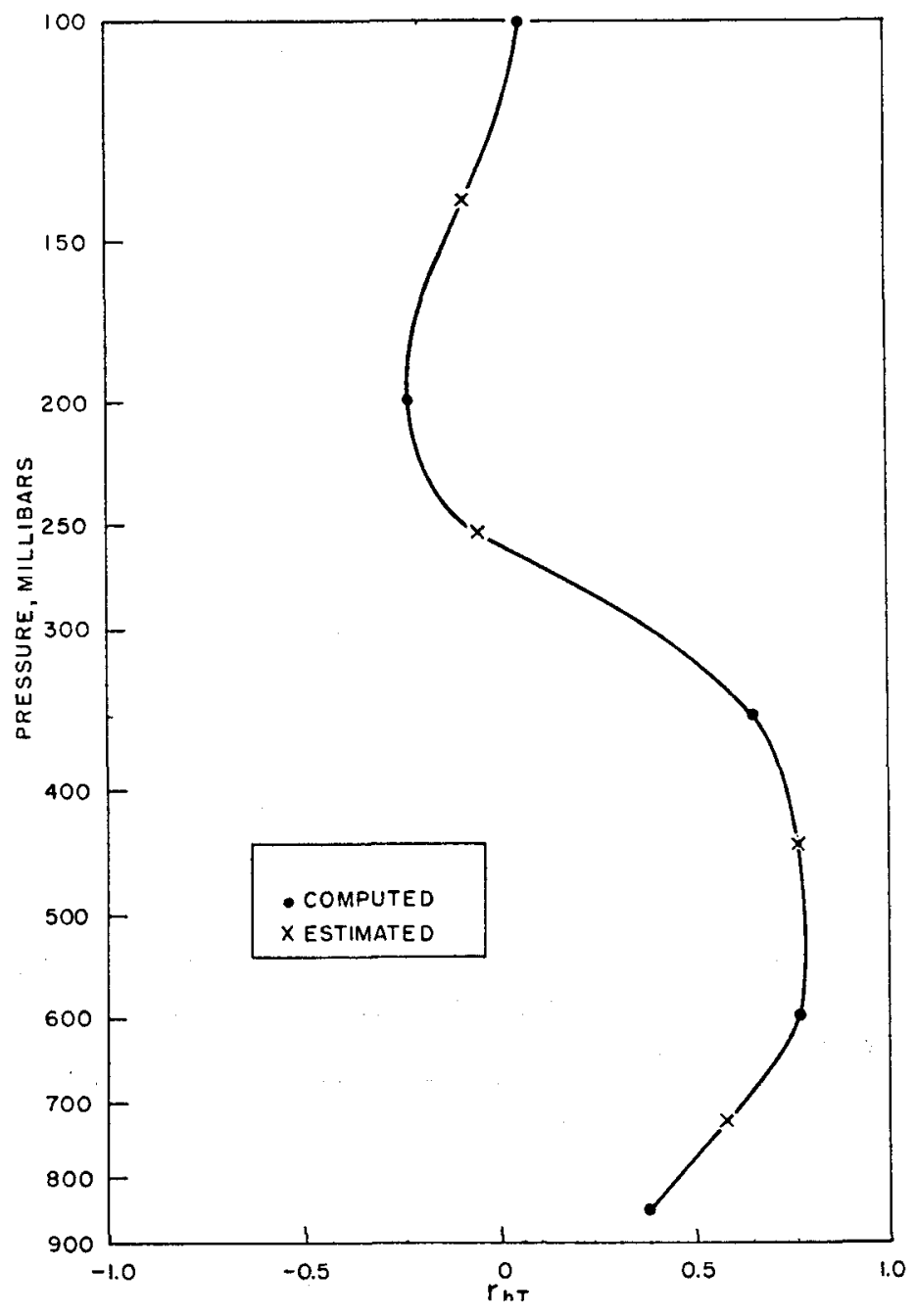

Figure 1.-Correlation coefficient between temperature change and height change of a constant pressure surface as computed and interpolated from $\sigma_{h}$ and $\sigma_{T}$ statistics.

\section{INTERPRETATION OF CORRELATION BETWEEN TEMPERATURE AND HEIGHT}

The remaining factor needed to evaluate the right side of equation (3) is $r_{P T}$. A formula for computing the coefficient of correlation where $x$ and $y$ are departures from their respective mean values is

$$
r=\left(\sum x y\right) / \sigma_{x} \sigma_{y}
$$

In the case wherein $x$ and $y$ are departures of height and temperature from their respective mean values, their standard deviations as well as their departures from the mean may be converted to constant level variations of pressure and temperature as shown in sections 3 and 4 . Since the same multipliers are applied to both numerator and denominator of the right hand side of the formula for computing $r$, the two coefficients of correlation are equivalent, and thus may be used interchangeably.

\section{APPLICATION OF THE DINES EQUATION}

Having given the necessary variables in the Dines 
equation we may proceed to the computation of the standard deviation of percentage density at Goose Bay at a level in the vicinity of $600 \mathrm{mb}$. as follows

$$
\begin{gathered}
\left(\frac{\sigma_{\rho}}{\rho}\right)^{2}=\left(\frac{8.44}{600}\right)^{2}+\left(\frac{6.96}{248.6}\right)^{2}-2(.76)\left(\frac{8.44}{600}\right)\left(\frac{6.96}{248.6}\right) \\
\frac{\sigma_{\rho}}{\rho}=1.95 \text { percent }
\end{gathered}
$$

This result may be compared with a computation of the standard deviation expressed as a percentage of mean density by actually interpolating to a fixed level between 600 and $550 \mathrm{mb}$. Such a procedure yielded 1.8 percent.

The procedure illustrated for the $600-\mathrm{mb}$. surface may be applied similarly at other elevations by using the following formula which combines the several steps expressed in general notation:

$$
\frac{\sigma_{p}}{\rho}=\left[\left(\frac{a \sigma_{h}}{P}\right)^{2}+\left(\frac{\left(b+\Gamma_{s}\right) \sigma_{T_{t}}}{b T}\right)^{2}-2 r_{h T}\left(\frac{a \sigma_{h}}{P}\right)\left(\frac{\left(b+\Gamma_{s}\right) \sigma_{T_{i}}}{b T}\right)\right]^{1 / 2}
$$

Here $a$ is the factor obtained from the Smithsonian Meteorological Tables for converting $\sigma_{h}$ to $\sigma_{P}, \Gamma_{s}$ is the assumed lapse rate (of NACA Standard Atmosphere, as used here), and other symbols are as previously defined.

The results of computations for Goose Bay at other pressure surfaces for January 1952 are shown in table 2.

As in the $600-\mathrm{mb}$. computation, $a$, the pressure change at constant level corresponding to a 10-meter height change of a constant pressure surface, was again obtained from the Smithsonian Meteorological Tables as shown in table 3 . The temperatures assumed in table 3 are not precisely the mean values given in table 1 , but they are within the limits defined by the standard deviation of temperature. This small departure from mean temperature has little effect on the final result. For example, if at $200 \mathrm{mb}$. the assumed temperature is varied $\pm 6^{\circ} \mathrm{C}$., the resulting change in density variability is less than 0.1 percent.

\begin{tabular}{|c|c|c|}
\hline Pressure (mb.) & Estimated $\frac{\sigma \rho}{\bar{\rho}} \times 100$ & Interpolated $\frac{\sigma_{\rho}}{\bar{\rho}} \times 100$ \\
\hline $\begin{array}{l}850 \\
6090- \\
300 \\
200\end{array}$ & $\begin{array}{ll}\text { (\%) } & \\
& 3.1 \\
& 1.95 \\
2.3 \\
4.1 \\
3.1\end{array}$ & $\begin{array}{l}2.7 \\
1.8 \\
1.9 \\
4.3 \\
3.0\end{array}$ \\
\hline
\end{tabular}

TABLE 2.-Standard deviation of percentage density for various pressure surfaces at Goose Bay, Labrador, January 1952 data

\begin{tabular}{|c|c|c|}
\hline Pressure (mb.) & $\begin{array}{c}\text { Assumed } \\
\text { temperature } \\
\text { ( C.) }\end{array}$ & $a(\mathrm{mb} . / 10 \mathrm{~m})$. \\
\hline $\begin{array}{l}850 \\
600 \\
350 \\
200\end{array}$ & $\begin{array}{l}-17 \\
-20 \\
-46 \\
-50 \\
-57\end{array}$ & $\begin{array}{l}1.12 \\
.81 \\
.52 \\
.306 \\
.16\end{array}$ \\
\hline
\end{tabular}

TABLE 3.-Values of. " $a$ " for various pressure and temperature combinations. From [4]

In the computations, the results of which are shown in table 2 , an isothermal lapse rate was assumed to exist in the vicinity of $200 \mathrm{mb}$. and $100 \mathrm{mb}$., assuming that these surfaces were in the stratosphere [7]. Under this assumption the standard deviations of temperature at constant level were further assumed to be equivalent to those at constant pressure.

\section{CONCLUSION}

A procedure has been developed for estimating the vertical distribution of the standard deviation of percentage atmospheric density at constant height using data summarized with reference to constant pressure levels without specifying in advance the altitudes for which the estimates are to be made. However from these data, curves of percentage density variability vs. altitude may be constructed from which the percentage variability may be interpolated at any desired altitude.

\section{REFERENCES}

1. W. H. Dines, "The Characteristics of the Free Atmosphere," Great Britain Meteorological Office, Geophysical Memoirs, No. 13, 1919.

2. C. E. Buell, "An Approximate Relation between the Variability of Wind and the Variability of Pressure or Height in the Atmosphere," Bulletin of the American Meteorological Society, vol. 38, No. 2, Feb. 1957, pp. 47-51.

3. William H. Klein, "A Hemispheric Study of Daily Pressure Variability at Sea Level and Aloft," Journal of Meteorology, vol. 8, No. 5, Oct. 1951, pp. 332-346.

4. Smithsonian Meteorological Tables, 6th Rev. Ed., prepared by R. J. List, Smithsonian Institution, Washington, D. C., 1951.

5. C. K. Stidd, "A Note on the Application of the Hydrostatic Equation to Atmospheric Statistics," Journal of Meteorology, vol. 11, No. 2, Apr. 1954, pp. 165-166.

6. A. F. Crossley, "Relation between the Standard Deviations of Temperatures at Constant Pressure and at Constant Height," Quarterly Journal of the Royal Meteorological Society, vol. 76, No. 329, July 1950, pp. 337-340.

7. National Advisory Committee for Aeronautics, "Standard Atmosphere-Tables and Data for Altitudes to 65,800 feet," NACA TR 1235, 1955. 